\title{
Por Uma Abordagem Mediática da Canção Popular Massiva
}

\author{
Jeder Silveira Janotti Junior'1 \\ Universidade Federal da Bahia \\ jeder@ufba.br
}

\begin{abstract}
Resumo: Uma rápida olhada sobre a circulação de produtos comunicacionais permite ao observador atento perceber que o excesso informacional também pressupõe segmentação. Este artigo procura realçar a importância da configuração mediática dos gêneros musicais através de suas condições de produção e reconhecimento, levando-se em consideração as performances, os cenários e os ritmos presentes nas canções populares massivas. Nesse sentido, parece ser mais do que atual a tentativa de compreensão do papel e da delimitação das canções como manifestações de determinados gêneros musicais, observando assim, os limites e as configurações da música popular massiva enquanto gênero mediatico.
\end{abstract}

Abstract: A fast look at the circulation of communication products allows the intent observer to perceive that the informational excess also estimates segmentation. This article looks for to enhance the importance of the mediatic configuration of the musical sorts through its conditions of production and recognition, taking in consideration the performances, the scenes and the rhythms gifts in the massive popular songs. In this direction, it more seems to be of the one than current the attempt of understanding of the paper and the delimitation of the songs as manifestations of determined musical sorts, thus observing, the limits and the configurations of massive popular music while mediatic sort.

Palavras-chave: gênero musical, música popular, performance, produção de sentido.

Keywords: musical sorts, popular music, performance, production of meaning.

\footnotetext{
${ }^{1}$ Professor do Programa de Pós-Graduação em Comunicação e Cultura

Contemporâneas(UFBA), onde coordena o Grupo de Pesquisa Mídia \& Música Popular Massiva.
} 


\section{Gênero Musical}

Não é incomum encontrarmos nos artigos e apresentações que envolvem a análise e compreensão da cultura mediática afirmações a respeito dos hibridismos, das interfaces e até da "imaterialidade" dos suportes comunicacionais na cultura contemporânea. Diante deste cenário parece até "retrógado" falar em gêneros musicais, mas, uma rápida olhada sobre a circulação de produtos comunicacionais, seja na internet, nas lojas especializadas ou na crítica musical permite ao observador atento perceber que o excesso informacional também pressupõe segmentação e que muitas vezes, até para filtrar esse excesso, tanto o campo da produção, como da circulação e consumo desses produtos se vale de rótulos extremamente codificados. Só para citar um exemplo, tocadores de MP3 como o $\operatorname{Ipod}^{2}$, ou programas de troca de arquivos musicais como o e-mule, permitem tanto a organização, bem como uma busca rápida de canções ${ }^{3}$ e faixas específicas a partir de sua classificação por gênero, mesmo a música eletrônica que seria uma espécie de anti-canção, é classificada a partir de uma série de rotulações: house, trance, trip-hop, etc. Nesse sentido, parece ser mais do que atual a tentativa de compreensão do papel e da delimitação das canções como manifestações de determinados gêneros musicais, observando assim, os limites e as configurações da música popular massiva ${ }^{4}$ enquanto gênero mediatico.

\footnotetext{
${ }^{2}$ Drive portátil desenvolvido pela Apple e que se tornou referência do consumo de música no arquivo MP3

3 Segundo Tatit: “ A canção popular é produzida na intersecção da música com a língua natural. Valendo-se de leis musicais para sua estabilização sonora, a canção não pode, de outra parte, prescindir do modo de produção da liinguagem oral. Daí a sensação de que um pouco de cada nova obra já existia no imaginário do povo, senão como mensagem final ao menos na maneira de dizer. Estudar a canção é no fundo aceitar o desafio de explorar essa área nebulosa em que as linguagens não são nem totalmente naturais (no sentido semiótico do terrmo), nem totalmente 'artificiais `e precisam das duas esferas de atuação para construir seu sentido" (1997:87).

$4 \mathrm{~A}$ idéia de música popular massiva está ligada às expressões musicais surgidas no século XX e quese valeram do aparato mediático contemporâneo, ou seja, instrumentos eletrificados,
} 
Se por um lado a noção de gênero remete à idéia de um modelo textual, paradigma de determinadas expressões discursivas, por outro, não se pode deixar de lado o papel que os aspectos materiais dos diversos mídias ocupam na própria denominação de gênero no campo comunicacional. Só para citar um exemplo, seria difícil manter a noção de música eletrônica independentemente da figura do DJ e da utilização dos samplers e pick ups na configuração dessas manifestações musicais5.

Desde já, parece importante destacar a ênfase mediatica na abordagem da noção de gênero. Em relação a este aspecto, o trabalho de Eliseo Verón é uma referência fundamental, uma vez que se valendo da Análise do Discurso e da Semiótica, ele procura ultrapassar os limites desses campos propondo uma abordagem comunicacional dos discursos sociais. Para Verón, os objetos culturais pressupõem condições materiais e simbólicas necessárias à confecção e à partilha dos valores por parte dos atores envolvidos nos processos de produção e consumo desses objetos. Tais condições dão conta, inclusive, da permanência ou das variações estilísticas dos objetos culturais em suas manifestações específicas. Assim: “(...) análise do discurso não é outra coisa que a descrição dos vestígios das condições produtivas nos discursos, sejam as de sua geração ou as que dão conta de seus efeitos" (VERÓN, 1996, p.127.).

Ancorados nos aspectos sociológicos do consumo dos produtos midiáticos, os Estudos Culturais apontam para o fato de que, em geral, reconhecemos parte dos produtos que circulam no campo da comunicação a partir de sua rotulação, ou seja, em geral se reconhece um filme, uma canção e os programas televisivos como configurações de um gênero particular:

técnicas de gravação e circulação tanto em suas condições de produção bem como em suas condições de reconhecimento. $\mathrm{O}$ termo se refere então às mutações ocorridas em parte da própria idéia de cultura popular e ao que os estudiosos de língua inglesa denominam música popular, uma vez que para eles não haveria mais uma distinção entre a cultura popular e a cultura popular massiva, que em português é, em alguns casos, denominada cultura pop. 5 Para uma abordagem das relações entre música e tecnologia ver PEREIRA DE SÁ e MARCHI (2003) e STERNE (2003). 
aventura, drama, rock, telejornal, série televisiva, telenovela, etc: “ O resultado deste reconhecimento é que o espectador/leitor/crítico orientará sua reação ao produto de acordo com as expectativas geradas pelo fato de reconhecer em primeiro lugar o seu gênero" (Fiske e outros, 1995: 165).

Em virtude das dificuldades de se mapear as fronteiras precisas dos gêneros a partir dos processos de direcionamento para um público potencial, pode-se então, a partir da perspectiva aqui apresentada, reconhecer que os gêneros são, antes de tudo, modelos (paradigmas) dinâmicos e não fórmulas ossificadas. Assim, para os Estudos Culturais:

\begin{abstract}
"É difícil isolar as características precisas de um determinado gênero e obter uma lista finita de todos os diferentes gêneros (seja para um único meio, seja para todos eles). Além disso, não é possível isolar características que indiquem distinções entre gêneros: não se trata somente de tema, nem somente de estilo, tampouco de estabelecer simplesmente convenções apropriadas a cada gênero. $O$ gênero é tudo isso ao mesmo tempo, mas como os paradigmas não se comportam como listas de supermercado, pode ocorrer que o simples fato de agregar um só filme ao gênero western, por exemplo, modifique todo esse gênero, mesmo que esse western exiba pouco das convenções reconhecidas, o estilo ou os assuntos tradicionalmente associados ao gênero" (FISKE e outros, 1995: 166).
\end{abstract}

Na verdade, os gêneros delimitam as produções de sentido, demarcando a significação e os aspectos ideológicos dos textos, bem como o alcance comercial (e o público alvo) dos produtos midiáticos. Toda definição de gênero pressupõe uma demarcação negativa e/ou comparativa com outros gêneros, ou seja, analisar um produto midiático através dessa perspectiva pressupõe perceber as relações entre esse produto e outros de diferentes gêneros, compará-lo com expressões canônicas ou similares dentro do mesmo paradigma. Os gêneros são dinâmicos justamente porque respondem a determinadas condições de produção e reconhecimento, indicativos das possibilidades de produção de sentido e de interação entre os modos de produção/circulação/consumo dos produtos midiáticos. Esse percurso minimizaria em parte a idéia de que os gêneros seriam pré-determinantes no 
processo de produção de sentido da cultura midiática. Assim, a configuração de determinados traços estilísticos de gênero musical em uma determinada canção define um processo de produção de sentido e, consequentemente, de comunicação que pressupõe regras formais e ritualizações partilhados por produtores e audiência. Isso não significa retornar à idealização do processo de recepção como lugar privilegiado da produção de sentido e sim, a necessidade de valorizar os diversos enlaces, estratégias e disputas que envolvem o trinômio produção/circulação/consumo no campo da música popular massiva: "Momentos de uma negociação, os gêneros não são abordáveis em termos de semântica ou sintaxe: exigem a construção de uma pragmática, que pode dar conta de como opera seu reconhecimento numa comunidade cultural" ( BARBERO, 1997: 302).

O desafio, então, é aplicar de maneira pontual a noção de gênero ao campo da música popular massiva, respeitando tanto os aspectos textuais, bem como os aspectos sociológicos que caracterizam a produção musical contemporânea. De início, pode-se perceber que o próprio modo como arrumamos nossas estantes e distribuímos nossas coleções de discos mostra muito sobre os valores que interiorizamos e sobre aquilo que consideramos positivo no mercado cultural contemporâneo. Mas as arrumações e as taxonomias que envolvem o consumo musical não estão situadas somente no campo da recepção. Uma olhada pelas grades de programação das rádios, pelas prateleiras das lojas de discos, pela circulação de música na internet, pelos releases das gravadoras e pela programação da MTV permite perceber que uma parcela importante da circulação e do consumo da música popular massiva está diretamente ligada aos aspectos textuais da canção e ao modo como as rotulações permitem ao consumidor organizar e reconhecer as valorações dos produtos culturais. 
Assim, é preciso reconhecer que boa parte daquilo que é consumido como rock ou MPB, por exemplo, pressupõe valorações que nem sempre estão ligadas diretamente aos aspectos musicais de uma determinada canção. Intérpretes como Raul Seixas e Cássia Eller são rotulados como roqueiros, mesmo que, em determinadas canções, a sonoridade se aproxime do universo musical da MPB. Nesse ponto é preciso desfazer as confusões em torno da noção de gênero, apontando pelo menos para dois importantes fatores das classificações genéricas da música popular massiva: 1) Aproximando-se da noção de gênero em sentido amplo, é possível notar a existência de arquigêneros no campo da música, assim, além de apontar para estratégias textuais ligadas ao campo da sonoridade, as noções de rock e MPB apontam também para aspectos sociológicos e ideológicos do campo da produção e recepção da música popular massiva; 2) Essas classificações estão diretamente ligadas a uma valoração que atravessa o universo da música popular massiva. Nos exemplos citados, é possível perceber uma certa aura de "autenticidade" que perpassa esses intérpretes. Ora, quando se fala em autenticidade, há a pressuposição de sua contrapartida, ou seja, músicos e canções que são considerados "cooptadas".

O sistema axiológico é uma das bases da cartografia da cultura musical. Um gênero musical dentro da cultura mediática é uma tendência para o investimento de determinadas valorações. Cada escolha é um posicionamento que contempla aspectos de demarcações territoriais e uma referência a atribuições de valores diferenciados, fundados na negação ou desqualificação de outros gêneros. Quando uma gravadora, um músico, um crítico ou um fã assumem ou negam determinado gênero, eles o fazem de acordo com referências que estão situadas à margem ou nos confins das estratégias textuais. O consumo musical envolve modos de gostar/não gostar, modos de audição específicos ligados às apropriações da musicalidade: 


\begin{abstract}
"É comum alguém dizer que ouviu um samba de Tom Jobim, um rock dos Titãs ou mais uma canção romântica de Roberto Carlos. Todas essas designações de gênero denotam a compreensão global de uma gramática. Significa que o ouvinte conseguiu integrar inúmeras unidades sonoras numa seqüência com outras do mesmo paradigma. Sambas, boleros, rocks, marchas são ordenações rítmicas gerais que servem de ponto de partida para uma investigação mais detalhada da composição popular" (TATIT, 1997:101).
\end{abstract}

É possível notar uma relação entre o rótulo musical e um suposto gosto do ouvinte, o que pressupõe uma certa afirmação sobre quem são os ouvintes para quem determinada música é dirigida. Em termos virtuais, os gêneros descrevem não somente quem são os consumidores, mas também as possibilidades de significação de um determinado tipo de música para um determinado público. Na rotulação está presente um certo modo de partilhar a experiência e o conhecimento musical. Mas como localizar as estratégias de comunicabilidade presente na música popular massiva?

Antes de mais nada, reconhecendo que toda rotulação pressupõe determinados horizontes de expectativa (SHUKER, 1999; WALSER, 1993). Ou seja, dependendo do gênero, elementos sonoros como distorção, altura e intensidade da voz, papel das letras, autoria e interpretação, harmonia, modo, melodia e ritmo ganham contornos e importâncias diferenciadas. Assim, se o solo de guitarra é fundamental em uma canção heavy metal, ele é completamente dispensável para uma banda de punk rock; se em uma canção MPB o vocal deve estar mais alto que os outros instrumentos, para que se possa apreciar a melodia e as palavras cantadas, para o rock, em geral, é mais importante um bom refrão e a mesma altura para todos os instrumentos ou, dependendo do gênero, a guitarra pode estar mais alta que os vocais. Levando em consideração a idéia de uma abordagem comunicacional da música, esse artigo propõe a utilização das idéias de performance, cenário e ritmo como um importantes operadores dos aspectos mediáticos da canção popular massiva, realçando o modo como esses aspectos são incorporado por gravadoras, 
músicos, críticos e fãs através da idéia de horizontes de expectativa e da mediação presentes na abordagem da música como gênero midiático.

\section{Performance, Cenário e Ritmo}

A abordagem proposta neste artigo não pretende se sobrepor ou desqualificar as interpretações musicológicas das canções, antes de mais nada reconhece-se a importância dos estudos que partem da notação musical e das análises imanentes do texto musical, mas quando se pretende trabalhar os aspectos mediaticos da canção popular massiva, deve-se levar em consideração o modo como a cultura medática, as indústrias fonográficas e a própria configuração do star system são apropriadas pelos ouvintes como parte integrante da produção de sentido da expressões musicais da cultura popular massiva, o que permite compreender como grande parte dos consumidores, críticos e músicos sem uma educação musical formal se apropriam dessas canções, transformando-as em marcos individuais e culturais do mundo contemporâneo.

A estrutura musical evoca sensações no ouvinte que estão conectadas imaginariamente a determinadas atmosferas. A produção de sentido da música popular massiva não deriva somente de uma configuração imperativa da canção, mas também de uma experiência cultural, um posicionamento sócio-cultural do próprio ouvinte. Parte, por exemplo, do consumo musical ligado aos DJs da música eletrônica ou ao último lançamento das estrelas da axé-music, incorporam imaginários e cenários diversos, bem como diferentes modos de lidar com a circulação destas canções na cidade contemporânea e, por conseguinte, com os cenários musicais pressupostos nestas expressões sonoras.

Assim, é possível observar também, para além dos deslocamentos financeiros, das hegemonias mercadológicas e das transformações 
tecnológicas que marcam a produção musical contemporânea, as relações entre o que as canções trazem à superfície como memória social. Nesse sentido, pode-se ponderar, por exemplo, que a penetração do estilos musicais juvenis no universo cultural das grandes cidades brasileiras está ligada ao modo como os ouvintes e fãs se apropriam da cidade (através das casas de shows, dos pontos de encontro e dos aparelhos de som), transformada então, pelas linguagens do rádio, da televisão e dos próprios aparelhos de telefonia móvel. É comum ouvir em nosso tecido urbano os encontros tensivos entre a sonoridade dos alto-falantes dos vendedores de frutas, dos ambulantes, dos interfones, dos aparelhos de som automotivos, dos avisos sonoros da marcha à ré dos caminhões, dos avisos de chamadas do celular. Dificilmente alguém associaria estes sons à música caipira ou às canções indígenas. Essas misturas e encontros criam indagações fundamentais para a compreensão dos diferentes cenários musicais: quem é o ouvinte presente nos espaços performáticos inscritos nas canções? Qual a tessitura urbana que está associada à determinada canção? Talvez só a partir da visibilidade de diferentes modos de agregação e exclusão, de reconhecimento e obliteração e, não menos importante, dos modos como esses processos são representados e apresentados pela cultura mediática é que se torna possível esboçar uma resposta inicial a esses questionamentos. Vale lembrar que não se trata necessariamente de cenários presentes em nossos mapas tradicionais. É possível falar dos cenários épicos do heavy metal, do sertão do baião, da Jamaica do reggae ou da metrópole do rap; na verdade não esses exemplos não são referências a territórios em sentido tradicional, e sim, espaços associados a certas sonoridades, ou melhor dizendo, paisagens (com suas contradições, anseios e faltas) presentes na música popular massiva. Pode-se afirmar, associando-se as idéias de Barbero (1997, 2004), que as tessituras urbanas são importantes mediadoras da produção de sentido da música contemporânea, sendo parte da própria materialidade das interações 
comunicativas oferecidas pela urbe e suas configurações territoriais e imaginárias.

Compreender a música popular massiva também significa ligá-la ao tecido coletivo, à reorganização das formas do habitar, do trabalhar e do brincar presente nos imaginários que cercam as cidades contemporâneas. Aqui, observa-se a emergência de cenários contraditórios que expressam ao mesmo tempo a hegemonia de algumas paisagens sonoras (Salvador e axé music, Rio de Janeiro e o samba enredo, Barretos e a música sertaneja, São Luiz e o reggae) e um cenário tensivo-fragmentário caracterizado pela existência de sonoridades diferenciadas no imaginário da cidade. Uma parte do consumo musical pressupõe certas experiências diante do espaço urbano. Muitas vezes as próprias denominações, por exemplo, música caipira de raiz ou música sertaneja, carregam traços que envolvem imaginários espaciais presentes nas performances das canções. No caso da música caipira, há uma valorização de uma certa quietude, de um mundo desarticulado das novas tecnologias e das "modernidades", já a nomenclatura música sertaneja remete, hoje, ao agrobusiness, aos rodeios, ao "mundo conectado" e pop dos grandes produtores de grãos. Enquanto a primeira se refere ao regional e suas especificidades, ao "sertão brasileiro", o segundo remete a paisagens globais dos campos de sojas e das máquinas agrícolas. É possível aferir então, pelo menos quando se trata de uma compreensão da música contemporânea, que mesmo quando tratam de um espaço geográfico comum, ou seja, como no exemplo citado acima, o Brasil agrícola, as manifestações culturais compreendem disputas, embates, distinções, hegemonias, deslocamentos, semelhanças e rupturas.

Desse modo, a música popular massiva não está relacionada somente às esferas do campo da produção. O sentido da música popular massiva também está ligado aos diversos modos de apropriação do produto por parte de músicos, ouvintes e produtores, sendo que a recepção é mediada por uma 
história social dos usos e interpretações que podem ser relacionadas aos cenários musicais presentes nas canções. Estes cenários são responsáveis pela ancoragem de novas sensibilidades, de canções agressivas ou "açucaradas" que circulam em meio aos sons, ruídos e ritmos que caracterizam a solidão, os encontros, a hegemonia e às faltas das paisagens contemporâneas.

Mas, todo cenário pressupõe uma determinada performance, que se desdobra em certas corporificações e configurações rítmicas da música popular massiva. Assim, a performance aponta para uma espiral que vai das codificações de gênero às especificidades da execução musical. Adaptando as idéias Zumthor (2000) ao campo da música popular massiva, pode-se afirmar que a idéia de performance engloba 1) o reconhecimento das expressões musicais de gênero, 2) a emergência de uma tensão entre os traços genéricos e a configuração desses traços em uma canção específica, 3) a implicação de um corpo como estratégia textual inscrita nos aspectos rítmicos da canção. Desse modo, mesmo que de modo virtual, a noção de performance está baseada na idéia de que a análise da música popular massiva pressupõe um processo comunicacional que se vale de certas regras formais e ritualizações partilhadas por produtores, músicos, críticos e audiência, direcionando certas experiências frente aos diversos gêneros musicais da cultura contemporânea.

A produção de sentido não poderia ser abordada sem levar em consideração o aspecto corporal da percepção e da experiência, uma vez que é impossível partir de uma investigação abstrata que desconsidere o papel do "corpo" na produção do sentido. Não só os corpos do intérprete e do receptor, também o corpo do objeto percebido, o suporte e o meio no qual está inserido. Para Fabbri (2000), mesmo quando o corpo não se faz presente fisicamente ele é experimentado em sua falta ou em sua ausência e afeta o ouvinte. Ao analisar a produção de sentido, portanto, é fundamental atentar para o corpo do produto, da música, dos músicos e dos ouvintes potenciais. A perfomatividade da voz ou do ato de "tocar" descreve um senso de 
personalidade, um modo peculiar de interpretar não só determinada música como as próprias convenções de gênero, um modo característico de corporificação das expressões musicais. Assim, a vocalização, a expressão rítmica e a interpretação de uma certa canção são “incorporações musicais”.

Nesse sentido, parte-se do pressuposto de que o ritmo é um dos componentes estruturadores da música popular massiva. O ritmo está intimamente ligado à conformação temporal dos sons: "Dar conta do ritmo de uma canção (que é, afinal, ouvi-la) significa participar ativamente de seu desdobramento e, ao mesmo tempo, confiar que esse desdobramento tem sido, ou será, definido, que nos levará a algum lugar" (FRITH, 1996:153). Assim, ritmo é a organização musical do tempo. Tal como na configuração métrica, a dimensão temporal é especializada na apreciação musical e está diretamente ligada a boa parte do apelo sensorial exercicido pelo música popular massiva em nosso cotidiano. Pode-se afirmar então, que a dança (virtual ou atualizada) de uma canção,ou pressuposta em um gênero musical, é uma interpretação rítmica dos sons:

“...) Meu ponto principal é que para a maioria da audiência de
música popular massiva o modo mais fácil de entrar na música é
quase sempre através do ritmo, através de movimentos regulares
do corpo (nós todos podemos participar da ação percussiva da
música, mesmo se nós não tivermos quaisquer habilidades
musicais). Seguindo essa perspectiva, a diferença entre as
músicas de base africana e européia descrevem somente as
convenções requeridas para os diferentes tipos de eventos
musicais: músicas mais participativas são 'ritmicamente' mais
complexas (e harmoniosamente seimples); músicas mais
contemplativas são 'ritmicamente' mais simples ( e
harmonicamente mais complexas)" (FRITH, 1996,142).

Na verdade, o que está em jogo na citação acima são "ideologias de audição", o que reforça a idéia de que o ato de dançar uma música não é um somente modo de expressar-se diante da música, mas um modo de ouvi-la. Mesmo na audição individual, digamos, de uma garota trancada no quarto ou percorrendo uma cidade com um walkman, está presente um modo de colocar-se em meio aos padrões rítimicos da sonoridade da canção. Pode-se 
dizer, então, que a dança (virtual ou atualizada) de uma canção, de um gênero musical, é uma interpretação rítmica dos sons:

\begin{abstract}
"A razão pela qual o ritmo é particularmente significante para a música popular massiva é que um tempo estável e um interessante padrão de batida oferece um dos modos mais fáceis de penetrar em um evento musical; eles possibilitam que o ouvinte sem prática instrumental responda 'ativamente', experiencie a música tanto corporalmente como uma questão mental. Isto não tem nada a ver com sair de si. Ao contrário, uma batida regular, algum senso de ordem, é necessário para o processo participativo em que o ritmo descreve ( nós estamos falando de tempo em sentido estrito como um a fonte de disciplina). O ritmo, como a dança, é sempre sobre o controle corporal (não a falta dele)" (FRITH, 1996: 143).
\end{abstract}

O ritmo é um dos componentes estruturadores da música que está voltado para a execução musical, para a materialidade sonora da canção. O ritmo está intimamente ligado à conformação temporal dos sons: "Dar conta do ritmo de uma canção (que é, afinal, ouvi-la) significa participar ativamente de seu desdobramento e, ao mesmo tempo, confiar que esse desdobramento tem sido, ou será, definido, que nos levará a algum lugar” (FRITH, 1996:153) A repetição, tão importante para análise da música, é fundamental para a demcarção narrativa da canção popular massiva. Essa demarcação envolve o encontro entre a métrica musical e a experiência de audição que abrange músicos e ouvintes. Não por acaso, tempo e andamento estão juntos quando se fala de execução musical, ou seja, o ritmo é “(...) organização musical do tempo" (FRITH, 1996: 153). Tal como na configuração métrica,a dimensão temporal é espacializada na apreciação musical. Os DJs e apreciadores de música eletrônica são ótimos exemplos de como música e ambiente transformam o espaço em referência musical; tanto é que além de metáforas espacias para nomear certos subgêneros, como house e jungle, eles se valem de um enorme aparato de iluminação, ambientação e demarcação dos espaços dançantes; assim o espaço é configurado como movimento, fato corroborado pela repetição rítmica e estrutural de grande parte da música eletrônica e da música popular massiva de um modo geral. 
A música sugere modos de estruturação do tempo. As acentuações, os tempos forte e fraco, as "batidas" estão relacionadas ao modo como experienciamos uma parte de nosso cotidiano. Não por acaso, é possível notar, por exemplo, em uma balada, elementos nostálgicos; enquanto, digamos, uma canção punk rock, pode ser classificada como "vivência do presente - aqui, agora”. E essas experiências trespassam as valorações que os diversos grupamentos de fãs acoplam ao processo auditivo, permitindo que as configurações rítmicas sejam consideradas "tediosas" ou "prazerosas”. Como afirma Frith:

\begin{abstract}
"A música não é, por natureza, racional ou analítica,; ela não nos fornece razões, mas experiências, e por um momento - por momentos - essa experiência envolve um tempo ideal, um ideal definido pela integração do que rotineiramente é mantido separado - o individual e o social, corpo e mente, mudança e permanência, a diferença e o mesmo, o que já passou e oque será, desejo e completude" (1996:157).
\end{abstract}

\title{
3-Considerações Finais
}

Traçar a rotulação de uma canção ou de um álbum envolve localizar diferentes estratégias comunicacionais que envolvem as convenções sonoras (o que se ouve), as convenções de performance (o que se vê, que corpo é configurado no processo auditivo), as convenções de mercado (como a música popular massiva é embalada) e convenções de sociabilidade (quais valores são “incorporados" e "excorporados" em determinadas expressões musicais). É possível então, lembrar que: “ (...) na construção de um autor de texto para a música popular massiva se fundem algumas combinações da voz, do corpo, da imagem e de detalhes biográficos" (BRACKETT, 1995:2). Não por acaso os atos performáticos da música popular massiva estão diretamente conectados ao universo dos gêneros. Ser um astro do cenário heavy metal ou da música axé pressupõe relações com a audiência que seguem as especificidades midiáticas e textuais dessas expressões musicais, bem como expectativas em relação aos cenários, corporificações e configurações rítmicas presentes nos 
gêneros musicais.Do mesmo modo que uma canção é ao mesmo tempo a música e sua respectiva performance, a audiência não consome somente as sonoridades, mas também a performance virtual inscrita nos gêneros midiáticos.

Para concluir, é possível inferir que a partir da tensão entre os aspectos textuais, midiáticos e mercadológicos presentes na noção de gênero musical pode-se perceber um jogo entre o corpo presente no gênero e sua “corporificação” particular, entre o personagem que protagoniza a canção, os personagens citados implicitamente e o próprio endereçamento do produto musical, que envolve tanto os aspectos imanentes da música, bem como os aspectos mediaticos da canção, compreendidas aqui como expressões que envolvem o corpo, o aparato técnico-midiático, a performance, o ritmo e as personagens integrantes deste jogo. Assumindo a complexidade desse processo, o pesquisador estará apto a reconhecer os limites do trabalho interpretativo, bem como a importância deste processo para a compreensão de uma dimensão relevante de nossas vivências diante da atual produção musical. Assim, acredita-se que abordar os fenômenos musicais como manifestações de determinados gêneros midiáticos é perceber como a música popular massiva é configurada como um produto cultural, que deixa pegadas de suas condições de produção e reconhecimento, que visa à produção de certos sentidos através de seus aspectos semióticos, sociais e ideológicos.

\section{Referências Bibliográficas}

BARBERO, Jesus M. Dos Meios às Mediações : comunicação, cultura e hegemonia. Rio de Janeiro : Ed. UFRJ, 1997.

. Ofício de Cartógrafo : travessias latino-americanas da comunicação na cultura. São Paulo :Edições Loyola, 2004. 
BRACKETT, David. Interpreting Popular Music. Berkeley/Los Angeles/London : University of California Press, 1995.

FABBRI, Paolo. El Giro Semiótico. Barcelona: Editorial Gedisa, 2000. FISKE, John et al . Conceptos Clave en Comunicación y Estudios

Culturales. Buenos Aires: Amorrotu Editores, 1995.

FRANÇA, Vera Regina Veiga. Programas "Populares" na TV: desafios metodológicos e conceituais, XIII Compós, São Bernardo (Umesp), 2004 (mimeo).

FREIRE FILHO, João. Das Subculturas às Pós-Subculturas Juvenis: música, estilo e ativismo politico. Revista Contemporânea. Salvador: Programa de Pós-Graduação em Comunicação e Cultura Contemporâneas/ UFBA, vol.3, $\mathrm{n}^{0} 3,2005$.

FRITH, Simon. Performing Rites: on the value of popular music.Cambridge/Massachusett: Havard University Press, 1998.

GOMES, Itânia. A Noção de Gênero Televisivo como Estratégia de Interação: o diálogo entre os cultural studies e os estudos da linguagem. In Revista Fronteiras de Estudos Midiáticos. Vol IV, $\mathrm{n}^{\mathrm{O}}{ }_{2}$, dez/2002. São Leopoldo: Programa de Pós-Graduação em Comunicação, Unisinos.

JANOTTI JR, Jeder.Aumenta que isso aí é rock and roll: mídia, gênero musical e identidade. Rio de Janeiro:E-papers, 2003a.

. À Procura da Batida Perfeita: a importância do gênero musical para a análise da música popular massiva. Revista Eco-Pós. Rio de Janeiro: Pós-Graduação em Comunicação e Cultura da Esola de Comunicação/ UFRJ, vol.6, n.2, 2003b, p. 31-46.

. Heavy Metal com Dendê: música e mídia em tempos de globalização. Rio de Janeiro, E-papers, 2004. 
. Dos Gêneros textuais, dos Discursos e das Canções: uma proposta de análise da música popular massiva a partir da noção de gênero mediático. IN: XIVCompós, 2005, Rio de Janeiro - UFF. Anais da XIV

\section{Compós.}

PEREIRA DE SÁ, Simone ; MARCHI, Leonardo de. Notas Para Se Pensar As Relações Entre Música e Novas Tecnologias da Comunicação. Revista EcoPós. Rio de Janeiro: Pós-Graduação em Comunicação e Cultura da Esola de Comunicação/ UFRJ, vol.6, n.2, 2003, p. 47-59.

SHUKER, Roy. Vocabulário de Música Pop. São Paulo: hedra, 1999. . Understanding Popular Music. London/New York:

Routledge,1994.

STERNE, Jonathan. The Audible Past: cultural origins of sound reproduction. Durham: Duke University Press,2003.

TATIT, luiz. Musicando a Semiótica. São Paulo: Annablume, 1997. . Semiótica da Canção: melodia e letra. São Paulo: Escuta, 1999.

. O Século da Canção. Cotia-SP:Ateliê Editorial,2004.

VERÓN, Eliseo. La Semiosis Social: Fragmentos de una teoría de la discursividade. Barcelona: Gedisa Editorial, 1996.

WALSER, Robert. Running With the Devil: power, gender and madness in heavy metal music. Hanover \& London: Wesleyan University Press, 1993. ZUMTHOR, Paul. Performance, Recepção e Leitura. São Paulo: Educ, 2000. . Tradição e Esquecimento. São Paulo: Huciitec, 1997. . A Letra e a Voz. São Paulo: Companhia das Letras, 1993. 